\title{
Avaliação da Implementação do Programa de Subvenção do Prêmio do Seguro Rural
}

\author{
Estela Alves de Medeiros ${ }^{1}$
}

Resumo: $O$ trabalho objetiva realizar avaliação da implantação do Programa de Subvenção do Prêmio do Seguro Rural, criado pelo Decreto n. 5.121/2004 e gerenciado pelo Ministério da Agricultura, Pecuária e Abastecimento. A partir de pesquisa documental e entrevistas com responsáveis por sua implementação, a avaliação apresenta os antecedentes de sua criação, principais características, a implantação e resultados alcançados. A seguir, os resultados do Programa frente aos objetivos propostos pela política pública e com relação aos critérios de suficiência de recursos, instrumentos de gestão e participação social foram avaliados. A conclusão da avaliação aponta uma eficácia parcial do Programa. $\mathrm{O}$ interesse pela adesão continua vigente, o que demonstra sua necessidade e importância. É preciso, contudo, avançar em alguns pontos, como o efetivo exercício do papel do Comitê Gestor Interministerial do Seguro Rural e a garantia dos recursos orçamentários de forma tempestiva.

Palavras-chaves: Seguro rural, política pública, avaliação.

Abstract: The study aims to evaluate the implementation of the Rural Insurance Premium Subsidy Program, created by the Decree number 5121/2004 and managed by the Ministry of Agriculture, Livestock and Food Supply (Brazil). With the support of documented research and interviews with leaders of the Program, this evaluation presents the background of its creation, main features, implementation and results achieved. After, the results of the goals of the Program proposed by the public policy and in regard of the criteria of sufficiency of resources, management tools and social participation were evaluated. The analysis points to a partial efficiency of the Program. The interest in joining the Program still prevails, demonstrating its need and importance. It is important, however, to step up at some points, as the effective exercise of the role of the Interministerial Steering Committee of the Rural Insurance and assurance of budgetary resources when it is necessary.

Key-words: Rural insurance, public policy, evaluation.

Classificação JEL: Q18.

1 Especialista em Políticas Públicas e Gestão Governamental do Ministério do Planejamento, Orçamento e Gestão. E-mail: estelaamedeiros@gmail.com 


\section{Introdução}

O setor agropecuário tem avançado nas últimas décadas no Brasil. Segundo dados dos Censos Agropecuários ${ }^{2}$ realizados pelo IBGE, da década de 70 até 2006 (data do último Censo Agropecuário), a agropecuária cresceu relativamente pouco em termos de estabelecimentos (de 4,9 milhões para 5,1 milhões), mas tanto a área total quanto a produção agrícola e pecuária tiveram aumento. A área passou de 294,1 milhões em 1970 para quase 330 milhões de hectares em 2006; a produção agrícola, de aproximadamente 34 para 60 milhões de hectares, e a produção de bovinos e bubalinos, de 78,6 milhões para 172,5 milhões de cabeças no mesmo período. Com a produção de aves, a elevação foi de 213 milhões em 1970 para 1.400 milhão de cabeças em 2006.

Porém, a atividade agropecuária está inserida em um conjunto de adversidades que a colocam em situação diferenciada quanto aos riscos enfrentados pelos produtores e demais agentes do sistema. As principais fontes de instabilidade para o setor associam-se aos riscos de produção, decorrentes de problemas climáticos, da incidência de pragas e doenças, e de preço. Além destes, existem ainda os riscos comuns a todas as atividades produtivas, como os tecnológicos e os devidos a oscilações na demanda. Sendo um setor

2 http://www.ibge.gov.br/home/estatistica/economia/ agropecuaria/censoagro/default.shtm que exige grandes investimentos, é natural que a atratividade dos agentes produtores esteja fortemente relacionada à amenização desses riscos. É preciso ressaltar, ainda, que o prejuízo na agricultura gera também perdas na sociedade como um todo, seja pela diminuição da disponibilidade de produtos agropecuários no mercado, seja pela redução em outras atividades relacionadas nos setores secundário e terciário da economia.

Para minimizar os riscos e seus efeitos na atividade agropecuária, faz-se necessária a consolidação de políticas específicas que atendam aos anseios dos produtores rurais. A própria Lei n. 8.171, de 17 de janeiro de 1991, conhecida como "Lei Agrícola", reconhece que a atividade agropecuária insere-se num contexto bastante particular, o que justifica a existência de uma política específica para o setor. Dentre outros temas, ela define o dever de proporcionar aos que se dedicam à atividade rural uma rentabilidade adequada e eliminar as distorções que afetam o desempenho das funções econômicas e sociais da agricultura. Neste contexto, insere-se a concessão da subvenção econômica ao Prêmio do Seguro Rural.

A proposta deste trabalho é avaliar a implantação do Programa de Subvenção ao Prêmio do Seguro Rural (PSR), no período de 2004 (criação do Programa) a 2010, focando na disponibilidade de recursos, na participação social em sua formulação ou implementação, e na funcionalidade dos instrumentos de gestão, especialmente o Comitê Interministerial de Gestão do Seguro Rural. 


\section{Metodologia}

Segundo Secchi (2010), a avaliação de uma política pública envolve o julgamento deliberado sobre a validade de propostas para a ação pública e também sobre o sucesso ou não dos projetos executados. Segundo o autor, é a fase do ciclo da política mais propícia para a produção de feedback sobre as fases antecedentes. Segundo Cotta (2001), as avaliações de políticas públicas são normalmente classificadas em função do tempo (antes, durante ou depois da implementação), da posição do avaliador em relação ao objeto avaliado (interna, externa ou semi-independente) e da natureza do objeto avaliado (contexto, insumos, processos e resultados). Por se tratar de avaliação de uma política pública que ainda está sendo implementada, o objeto deste trabalho é uma avaliação in itinere, que apresentará os avanços em relação aos objetivos propostos da política e também levantará o estado do Programa com relação à disponibilidade de recursos, participação social e instrumentos de gestão.

Secchi (2010) afirma que as avaliações necessitam de critérios que servem de mecanismos lógicos para as escolhas e julgamentos. Os principais critérios usados nas avaliações, segundo ele, são: economicidade (nível de utilização dos recursos), eficiência econômica (relação entre recursos utilizados e produtividade), eficiência administrativa (nível de conformação da execução dos métodos preestabelecidos), eficácia (nível de alcance das metas ou objetivos preestabelecidos) e equidade (homogeneidade de distribuição de benefícios/punições entre os destinatários de uma política pública). Ainda segundo Secchi (2010), os critérios são operacionalizados por meio de indicadores. No caso deste estudo, o principal enfoque é nos alcances dos resultados conforme as diretrizes propostas pelo Decreto n. 5.121/2004, que regulamenta o Programa de Subvenção ao Prêmio do Seguro Rural, a saber: promover a universalização do acesso ao seguro rural, assegurar o papel do seguro rural como instrumento para a estabilidade da renda agropecuária e induzir o uso de tecnologias adequa- das e modernizar a gestão do empreendimento agropecuário. Portanto, trata-se de uma avaliação de eficácia do Programa. Além disso, também se avaliará a suficiência de recursos, seus instrumentos de gestão e a participação social na implementação da política pública.

Por ser tratar de um Programa recente (cinco anos), optou-se por uma pesquisa qualitativa ao invés de metodologias quantitativas, como análise econométrica. A metodologia a ser utilizada neste estudo, portanto, é a pesquisa de documentos oficiais produzidos pelo Ministério da Agricultura, Pecuária e Abastecimento (Mapa), como normas, relatórios estatísticos do Programa e atas de reunião, e entrevistas com os responsáveis pela implementação do Programa. A legislação e os relatórios foram obtidos no sítio eletrônico do Ministério (www.agricultura.gov.br). As atas de reuniões foram disponibilizadas pelo Departamento de Gestão do Risco Rural da Secretaria de Política Agrícola do Mapa. A seguir, serão realizadas análise de conteúdo e análise de discurso do material levantado. As informações serão comparadas com os indicadores de desempenho verificados a partir deste material, de modo a possibilitar a avaliação do Programa.

Sabatier (1993, apud Secchi, 2010) sublinha que, em geral, os efeitos de uma política pública só são tangíveis após dez anos de sua implementação, pois elas demandam um tempo de ajustamento, de assimilação de seus propósitos e de mudança de comportamento dos atores afetados por ela. Porém, apesar do pouco tempo de implementação do PSR, a perspectiva deste estudo é que os dados coletados possibilitarão sua avaliação inicial.

\section{Programa de Subvenção ao Prêmio do Seguro Rural}

Esta seção se subdivide em três partes. A primeira trata dos antecedentes da criação do Programa. A segunda apresenta suas características. Por fim, apresentar-se a implementação do Programa no período 2004-2010. 


\subsection{Antecedentes}

O seguro rural é um importante instrumento de mitigação do risco na agropecuária, pois permite ao produtor proteger-se de perdas decorrentes de fenômenos climáticos adversos ou de doenças, podendo, ainda, garantir renda ao produtor em caso de sinistro (ALMEIDA, 2007). Segundo Guimarães e Nogueira (2008), nos Estados Unidos, país onde o seguro rural é mais difundido, as medidas de apoio a este instrumento ocorrem desde 1930. Mesmo assim, apenas na década de 90 é que a área coberta representou uma parcela significativa da área plantada. Este resultado só foi obtido, no entanto, em função do papel do governo norte-americano, que subsidiou não apenas o Prêmio do Seguro, mas também as despesas operacionais e administrativas de seguradoras, além de outras ações de apoio ao Programa.

No Brasil, segundo Ozaki (2005), em 1948, tramitou no Senado Federal um projeto de lei que estabeleceu as bases do seguro agrícola no País. Parte do projeto se transformou na Lei n. 2.168/54, que institui o seguro agrário destinado à preservação das colheitas e dos rebanhos contra a eventualidade de riscos inerentes à atividade. Além disso, a lei define o Instituto de Resseguros do Brasil (IRB) como ressegurador desta modalidade de seguro e cria a Companhia Nacional de Seguro Agrícola (CNSA). Ainda segundo Ozaki (2005), no texto do projeto de lei se evidenciava uma preocupação não só com o produtor, mas também com as instituições que operassem no setor.

Segundo Almeida (2007), dentre outros motivos, a CNSA falhou em seus objetivos por ofertar produtos sem levar em consideração as peculiaridades de cada região produtora. A companhia foi dissolvida em 1966, quando o Decreto-Lei n. 73/66 instituiu o Sistema Nacional de Seguros Privados (SNSP). O Decreto ainda criou o Fundo de Estabilidade do Seguro Rural (FESR), cujo objetivo principal é garantir a estabilidade dessas operações e atender à cobertura suplementar dos riscos de catástrofe. A norma também garan- tiu às operações de Seguro Rural isenção tributária irrestrita, de quaisquer impostos ou tributos federais, de modo a reduzir o custo do Prêmio para o produtor. Almeida (2007) destaca, ainda, a criação, em 1969, da Companhia de Seguros do Estado de São Paulo, que atuou durante 30 anos no ramo do seguro agrícola, chegando, inclusive, a estender as operações para outros estados. Ela encerrou suas atividades neste ramo em 2004.

Como o FESR não conseguiu estender o seguro rural para outras Unidades da Federação diferentes de São Paulo e dos estados da região Sul, segundo Almeida (2007), em 1973, o governo federal criou, por meio da Lei n. 5.969/1973, o Programa de Garantia da Atividade Agropecuária (Proagro). Este Programa visa garantir, principalmente aos pequenos e médios produtores rurais, o pagamento do financiamento de custeio agrícola, ou a indenização de recursos próprios, do produtor cuja lavoura tenha passado por sinistro em função de fenômenos naturais, pragas e doenças. Segundo Ozaki (2005), a medida foi criada para oferecer ao setor produtivo segurança quanto ao permanente fornecimento de crédito. A partir de 1997, sob a regulamentação da nova Lei Agrícola (Lei n. 8.171/91), segundo Rosseti (2001), o pagamento relativo ao Proagro passou a ter como exigência a observância das regras de plantio definidas pelo zoneamento agrícola de risco climático.

Além da ineficiência do FESR, outra razão identificada para o não avanço do seguro rural no Brasil era a ausência de cultura do produtor em contratar o seguro rural (ALMEIDA, 2007). De maneira geral, os produtores entendiam que o seguro rural era um custo a mais de produção. A demanda se restringia às regiões de climas mais instáveis ou às culturas com riscos mais elevados, o que afetava a carteira das seguradoras, conforme demonstrado na Tabela 1, sobre o período de julho de 1995 a dezembro de 2005. Pelos dados, percebe-se que os seguros nas modalidades Pecuária e Florestas, que correspondem a menos de 5\% do arrecadado com seguro rural, trouxeram lucro para os agentes securitários (diferença entre Prêmio arrecadado e sinistro pago) 
Tabela 1. Diferença entre prêmios recebidos e sinistros pagos pelas seguradoras, por modalidade, no período de julho de 1995 a dezembro de 2005

\begin{tabular}{cccc}
\hline \multirow{2}{*}{ Modalidade } & \multicolumn{3}{c}{ De julho/95 a dezembro/2005 } \\
\cline { 2 - 4 } & Prêmio em $R \$$ mil $(a)$ & Sinistro em mil $R \$(b)$ & $(a)-(b)$ em mil $R \$$ \\
\hline Agrícola & $263.826,34$ & $503.152,16$ & $-239.325,82$ \\
Pecuário & $1.053,35$ & 233,29 & 820,06 \\
Aquícola & 0,00 & 0,00 & 0,00 \\
Florestas & $12.198,60$ & $2.938,30$ & $9.260,30$ \\
Total & $277.078,29$ & $506.323,75$ & $-229.245,46$ \\
\hline
\end{tabular}

Fonte: Ministério da Agricultura, Pecuária e Abastecimento, 2010.

na ordem de $\mathrm{R} \$ 10,08$ milhões. O seguro agrícola, por outro lado, causou prejuízo de mais de $\mathrm{R} \$ 239$ milhões para as seguradoras no período.

A concentração de risco encarecia o custo do prêmio, aumentando o desinteresse dos produtores pelo mecanismo. Era preciso, então, baratear o prêmio do seguro e ampliar o número de segurados, de modo a atender produtores e seguradoras. Segundo análise do Ministério da Agricultura, Pecuária e Abastecimento, na falta do seguro agrícola, o governo não tem alternativa senão compensar as quedas de receita decorrentes de fenômenos climáticos com a prorrogação das dívidas do crédito rural. O volume de dívidas rurais acumuladas impõe ao Tesouro Nacional um ônus maior do que aquele que se gastaria com o pagamento parcial do custo anual de contratação do seguro agrícola.

Desta forma, o governo elegeu como uma de suas prioridades a ampliação da cobertura securitária privada no meio rural. Segundo informações das entrevistas realizadas, as discussões sobre a concessão de subvenção ao Prêmio do Seguro Rural se iniciaram no final do segundo Governo Fernando Henrique Cardoso (20012002) e ganharam forma em 2003, já no Governo Lula. O ministro Roberto Rodrigues determinou que este seria um dos temas prioritários de sua gestão. Ainda em 2003 foi criado o Fórum Permanente do Seguro Rural, no qual participava, além dos membros governamentais, o mercado segurador (por meio da Federação Nacional das Empresas de Seguros Privados e Capitalização Fenaseg), as Federações Estaduais de Agricultura e as Secretarias Estaduais de Agricultura. O grupo contou, não só com o apoio, mas também com a participação ativa do ministro Rodrigues em todos os seus encontros. A mobilização dos atores envolvidos neste fórum foi decisiva para que o projeto de lei fosse elaborado, enviado para o congresso e aprovado, em regime de urgência, ainda em 2003. A Lei n. 10.823, de 19 de dezembro de 2003, autoriza a concessão de subvenção econômica ao Prêmio do Seguro Rural. Além disso, a lei cria, no âmbito do Mapa, o Comitê Gestor Interministerial do Seguro Rural (CGSR). Após a aprovação da lei, o Ministério trabalhou na proposta de regulamentação da política pública. Em 2004, o Decreto n. 5.121 criou o Programa de Subvenção ao Prêmio do Seguro Rural (PSR).

\subsection{Características do Programa}

O PSR tem como objetivo subsidiar parte do Prêmio do Seguro Rural, de modo a ampliar a cobertura securitária privada no campo. Assegurar o papel do seguro rural como instrumento para a estabilidade da renda agropecuária, induzir o uso de tecnologias adequadas e modernizar a gestão do empreendimento agropecuário são outros objetivos do PSR, segundo o Decreto n. $5.121 / 2004$.

A operacionalização do Programa é responsabilidade do Ministério da Agricultura, Pecuária e Abastecimento, e seu público-alvo são produtores rurais (pessoas físicas ou jurídicas), que devem contratar o seguro rural diretamente com as seguradoras autorizadas pela Superintendência 
de Seguros Privados (Susep) e cadastradas junto ao Mapa. Este repassa para as seguradoras um percentual do prêmio do seguro contratado, o que reduz o valor a ser pago pelo produtor rural à seguradora. A subvenção ao Prêmio do Seguro Rural leva em consideração aspectos como as modalidades, os tipos de cultura e espécies animais, conforme demonstrado na Tabela 2, que apresenta os percentuais e limites financeiros vigentes do PSR. Conforme será visto na próxima seção, os produtos atendidos, assim como os percentuais e limites financeiros, foram alterados ao longo do tempo pelo Comitê Gestor do Programa, objetivando ampliar o número de beneficiários.

Visando cumprir o objetivo de induzir o uso de tecnologias adequadas e modernizar a gestão do empreendimento agropecuário, o PSR estabeleceu como condicionalidade para o recebimento da subvenção a observância dos indicativos do zoneamento agrícola de risco climático. Este zoneamento, divulgado pelo Mapa, objetiva orientar agricultores, agentes financeiros e seguradoras sobre a melhor época e tecnologia a ser utilizada no plantio das lavouras. É mais um instrumento que contribui para a minimização de riscos da atividade agrícola, uma vez que permite a identificação e dimensionamento dos riscos climáticos.
Como ferramenta de gestão, a citada lei criou um Comitê Gestor Interministerial do Programa, composto por integrantes dos órgãos governamentais envolvidos no processo: Mapa, Susep, Ministério da Fazenda (MF), Ministério do Planejamento, Orçamento e Gestão (MP), Ministério do Desenvolvimento Agrário (MDA), Secretaria do Tesouro Nacional (STN/MF) e Secretaria de Política Agrícola (SPA/Mapa). Cabe a este Comitê aprovar, dentre outros: a) os percentuais sobre o Prêmio do Seguro Rural e os valores máximos da subvenção econômica; b) as culturas vegetais e espécies animais objeto da subvenção; c) as regiões a serem amparadas pelo benefício; d) as condições técnicas a serem cumpridas pelos beneficiários e e) a proposta de Plano Trienal para o Programa.

\subsection{Implementação}

Após a aprovação da lei e do decreto que regulamentam o PSR, o Mapa iniciou um conjunto de atividades para implementar o Programa. Dentre elas, pode-se citar a discussão com o mercado segurador, a elaboração de estudos para operacionalização da subvenção e como distribuir o valor da subvenção às companhias seguradoras,

Tabela 2. Percentuais e limites financeiros do Programa de Subvenção ao Prêmio do Seguro Rural, por tipo de atividade, 2010

\begin{tabular}{|c|c|c|c|}
\hline Atividade & Produtos & $\begin{array}{l}\text { Percentual } \\
\text { subvenção }\end{array}$ & $\begin{array}{l}\text { Limite } \\
\text { financeiro }\end{array}$ \\
\hline Agrícola Grupo I & Feijão, milho de segunda safra e trigo & 70 & $\mathrm{R} \$ 96.000,00$ \\
\hline Agrícola Grupo II & $\begin{array}{l}\text { Ameixa, aveia, canola, caqui, cevada, centeio, figo, kiwi, linho, maçã, } \\
\text { nectarina, pera, pêssego, sorgo, triticale e uva. }\end{array}$ & 60 & \\
\hline Agrícola Grupo III & Algodão, arroz, milho e soja & 50 & \\
\hline Agrícola Grupo IV & $\begin{array}{l}\text { Abacate, abacaxi, abóbora, abobrinha, alface, alho, amendoim, atemoia, } \\
\text { banana, batata, berinjela, beterraba, cacau, café, caju, cana-de-açúcar, cebola, } \\
\text { cenoura, cherimoia, chuchu, couve-flor, ervilha, escarola (chicória), fava, } \\
\text { girassol, goiaba, graviola, jiló, laranja, lichia, lima, limão e demais citros, } \\
\text { mamão, mamona, mandioca, manga, maracujá, melancia, melão, morango, } \\
\text { pepino, pimentão, pinha, quiabo, repolho, sisal, tangerina, tomate, vagem, } \\
\text { demais hortaliças e legumes. }\end{array}$ & 40 & \\
\hline \multicolumn{2}{|r|}{ ( } & 30 & $\mathrm{R} \$ 32.000,00$ \\
\hline \multicolumn{2}{|l|}{ Florestas } & 30 & $\mathrm{R} \$ 32.000,00$ \\
\hline \multicolumn{2}{|l|}{ Aquícola } & 30 & $\mathrm{R} \$ 32.000,00$ \\
\hline \multicolumn{3}{|c|}{ Valor Máximo Subvencionável } & $\mathrm{R} \$ 192.000,00$ \\
\hline
\end{tabular}

Fonte: Ministério da Agricultura, Pecuária e Abastecimento, 2010. 
o registro na Susep, a discussão de um Programa de Resseguro dos Produtos de Seguro e a elaboração de proposta do Plano Trienal do Seguro Rural, cujo objetivo é conferir maior previsibilidade às ações do governo, dando ao mercado segurança para seus investimentos em estrutura e planejamento. A proposta do Plano Trienal foi, inclusive, discutida com o setor produtivo e securitário, conforme ressaltado nas Atas da $3^{\underline{a}}$ e $4^{\underline{0}}$ reuniões ordinárias do Comitê Gestor Interministerial do Seguro Rural.

A parte institucional do Programa também foi organizada. Primeiramente, o Ministério formalizou o Comitê Gestor previsto em lei. Sua primeira reunião ocorreu em 18 de agosto de 2004, conforme ata da primeira reunião. Além da aprovação de regimento interno do Comitê, nesta primeira reunião também foram criadas três Comissões Consultivas Permanentes, segundo sugestão do Fórum Permanente de Seguro Rural, a serem compostas também com membros do setor privado: de Garantias Securitárias, de Produtos de Seguro e de Pesquisas Agropecuárias e Zoneamento Agrícola. Desde sua criação, o Comitê Gestor se reuniu apenas 13 vezes. De acordo com suas atas, disponibilizadas pelo Departamento de Gestão do Risco Rural do Ministério da Agricultura, os encontros foram mais frequentes em seu início, para organização e aprovação de seu regimento interno e da operacionalização do PSR. Em seguida, as reuniões passaram a ocorrer de forma esporádica, quando há necessidade de aprovar regulamentos e alterações no Programa. As comissões aprovadas não foram implementadas, conforme evidências das atas e de entrevistas com gestores do Programa.

Em seguida, o Ministério criou, em 2005 (Decreto n. 5.351/2005), dentro da Secretaria de Política Agrícola, o Departamento de Gestão de Risco Rural. Uma de suas coordenações-gerais é responsável pela implementação do PSR, além de ser a Secretaria Executiva do CGSR. A Coordenação-geral do Seguro Rural, segundo as atas de reunião do Comitê Gestor analisadas, é quem faz, efetivamente, a gestão do PSR.
Uma questão a ser observada é que, ainda hoje, o Mapa não conta com um sistema completo para a gestão do Programa, segundo informações da Coordenação-geral. O Ministério depende, em alguns casos, das informações fornecidas por outras instituições, o que pode comprometer o processo decisório.

Segundo os entrevistados, a última ação institucional visando à agregação das partes interessadas na formulação de políticas públicas de crédito e minimização de risco foi a instalação da Câmara Temática de Financiamento e Seguro do Agronegócio, em julho de 2004. Na ocasião, foi indicado como presidente da Câmara o então presidente da Bolsa de Mercadorias e Futuros, e para secretário executivo o secretário de Política Agrícola da época. Segundo informações do Departamento de Gestão do Risco Rural, a Câmara Temática pouco se reuniu até 2010 e acabou sendo desativada. Em junho de 2011 foi instalada nova Câmara Temática, exclusiva para Seguros do Agronegócio. Na reunião inicial foram definidas as datas de duas reuniões ordinárias para o ano vigente. A Câmara contará com, aproximadamente, 30 instituições públicas e privadas, inclusive representantes dos produtores rurais, segundo os entrevistados.

A ata da primeira reunião ordinária do Comitê Gestor aponta que a primeira tentativa de alocação do montante de subvenção para as seguradoras se deu por meio do mecanismo de leilões, operacionalizado pela Conab (Companhia Nacional de Abastecimento), empresa pública vinculada ao Mapa. A intenção era utilizar um mecanismo rápido e transparente, que estimulasse o livre mercado, no qual seriam leiloadas cotas de subvenção para determinadas culturas e regiões. Num segundo momento, o mecanismo possibilitaria a participação direta de cooperativas e produtores rurais. A dificuldade para se implementar, no curto prazo, um sistema informatizado para o gerenciamento, controle e fiscalização das operações foi outra questão ponderada pelo Ministério para se recorrer ao mecanismo de leilões. As regras para o leilão foram aprovadas pelo Comitê Gestor. 
Porém, conforme descrito nas atas das reuniões seguintes do Comitê Gestor, a utilização do leilão como mecanismo de concessão da subvenção não foi bem-sucedida. Houve, então, a necessidade de se adequar a operacionalização do Programa. Decidiu-se pelo modelo vigente, no qual o produtor rural contrata diretamente a apólice de seguro de qualquer das seguradoras cadastradas no PSR. A subvenção é repassada diretamente à seguradora. Outra modificação efetuada é que o seguro deixou de considerar o ano-safra (julho de um ano até junho do ano seguinte) e passou a considerar o ano civil. Isso possibilitou ter anualmente a contratação de duas subvenções (inverno e verão). $\mathrm{O}$ resultado esperado, segundo os entrevistados, era integrar o produtor do Centro-Oeste nas operações de seguro rural.

Em 2006, o Mapa elaborou seu Plano Estratégico para o período 2006-2015 (BRASIL, 2009). Segundo os entrevistados, a ampliação do PSR foi considerada uma das iniciativas estratégicas do Ministério. A capacitação de agentes do setor securitário e a aprovação dos marcos regulatórios que complementam o Programa são ações previstas na Iniciativa Estratégica. Além de se constituir em projeto corporativo, o PSR passou a ser acompanhado pela Alta Liderança do Ministério por meio de indicador de desempenho que mensura a área agrícola coberta pelo seguro rural. Em 2015, segundo o Relatório de Gestão Estratégica (BRASIL, 2011b), o Mapa espera alcançar cobertura securitária de $50 \%$ da área agrícola, principalmente de grãos, o que cor- responde a aproximadamente 30 milhões de hectares. Em 2010, este índice alcançou 7,83\%.

Conforme análise das atas das reuniões ordinárias do Comitê Gestor, as concessões de subvenção receberam ajustes, ao longo do tempo, com relação às culturas seguradas, os percentuais de subvenção e o limite financeiro, o que contribui para a ampliação de beneficiados pelo Programa. Outra importante causa do aumento dos segurados, segundo os entrevistados, foi a criação de programas de subvenção em alguns estados, de modo a complementar o prêmio subvencionado pelo governo federal. Além de São Paulo, que tem longa tradição de seguro rural, conforme visto nos antecedentes, hoje há programas de subvenção em Minas Gerais e Paraná, estados com grande importância agrícola. Bahia e Mato Grosso do Sul estão em fase de desenho de seus programas.

Os resultados alcançados demonstram a ampliação do número de produtores atendidos, da área segurada e do valor médio subvencionado ao longo do tempo, conforme demonstrado na Tabela 3.

O Programa permitiu ampliar a oferta de seguro rural para todas as regiões produtoras, já estando presente em 18 estados da Federação, beneficiando mais de 70 culturas na modalidade agrícola, além de contemplar também as modalidades de seguro rural pecuário, aquícola e de florestas. Apesar dos números registrados, a disponibilização de recursos orçamentários destinados à subvenção ainda não são suficientes para atender a demanda por essa modali-

Tabela 3. Evolução do PSR de 2005 a 2010

\begin{tabular}{lcccccc}
\hline & $\mathbf{2 0 0 5}$ & $\mathbf{2 0 0 6}$ & $\mathbf{2 0 0 7}$ & $\mathbf{2 0 0 8}$ & $\mathbf{2 0 0 9}$ & $\mathbf{2 0 1 0}$ \\
\hline Demanda seguradoras (R\$ milhões) & - & 61,00 & 114,00 & 158,00 & 272,00 & 460,00 \\
Orçamento aprovado (R\$ milhões) & 10,00 & 61,00 & 100,00 & 160,00 & 272,00 & 328,00 \\
Orçamento disponibilizado (R\$ milhões) & 10,00 & 61,00 & 100,00 & 160,00 & 172,00 & 238,00 \\
Valores utilizados (R\$ milhões) & 2,30 & 31,10 & 60,90 & 157,50 & 260,00 & 198,28 \\
Capitais segurados (R\$ milhões) & 126,60 & $2.869,00$ & $2.706,00$ & $7.209,00$ & $9.684,00$ & $6.541,63$ \\
Área segurada (ha) & 68.148 & 1.560 .549 & 2.276 .245 & 4.762 .902 & 6.669 .296 & 4.787 .641 \\
$\mathrm{~N}^{\circ}$ produtores atendidos (unidade) & 849 & 16.653 & 27.846 & 43.642 & 56.306 & 38.211 \\
Valor médio de subvenção - por produtor (R\$) & $2.709,07$ & $1.867,53$ & $2.187,03$ & $3.608,91$ & $4.600,00$ & $5.189,08$ \\
\hline
\end{tabular}

Fonte: Ministério da Agricultura, Pecuária e Abastecimento, 2010. 
dade de garantia. De 2005 a 2008, os recursos foram suficientes para cobrir praticamente toda a demanda apresentada pelas seguradoras, segundo as informações da Tabela 3. Porém, a partir de 2009, quando o produtor rural passou a demonstrar mais confiança no seguro, os valores orçamentários disponibilizados deixaram de atender a demanda. Em 2010, a diferença entre o demandado pelas seguradoras e o liberado pelo Ministério foi de mais de R 260 milhões. É preciso ressaltar as diferenças entre os valores orçamentários apresentados na tabela. O orçamento aprovado é aquele que consta da Lei Orçamentária Anual. O disponibilizado é o estabelecido pelo Ministério do Planejamento, Orçamento e Gestão após contingenciamento. Por fim, os valores utilizados representam os recursos financeiros efetivamente liberados pela Secretaria do Tesouro Nacional. Portanto, há necessidade de aumento desses recursos para que o Programa cumpra seu objetivo de ampliação do universo segurado.

Outra dificuldade levantada pelos gestores do Programa entrevistados é a liberação de recursos financeiros. É preciso garantir que os desembolsos financeiros ocorram tempestivamente, ou seja, no momento necessário. Recursos suficientes e tempestivos, na visão deles, possibilitarão a ampliação da área segurada, a mitigação dos efeitos causados pelos riscos da atividade agrícola e pecuária e a consolidação do mercado segurador agropecuário privado no País. As questões orçamentárias do Programa constam, desde 2006, das reuniões do Comitê Gestor e desde 2009, segundo os entrevistados, dos pontos de atenção das reuniões estratégicas do Ministério. Para alcançar a meta de cobertura do PSR em 2015, o Mapa deverá dispor para as subvenções do prêmio, segundo informações da Secretaria Executiva do Comitê Gestor, aproximadamente R\$ 3 bilhões.

Os gestores entrevistados destacaram, ainda, dois pontos que podem contribuir com a ampliação do PSR: a abertura do mercado ressegurador, ocorrida em abril de 2008 (Lei Complementar n. 126/2007 e Resolução Conselho Nacional de Seguros Privados n. 168/2007), que acabou com o monopólio do IRB neste tema; e a aprovação do Fundo de Catástrofe do Seguro Rural (Lei Complementar n. 137/2010). Se no início da operacionalização do PSR o País contava com apenas um ressegurador (IRB), atualmente, há 10 resseguradoras atuando no Programa e outras que demonstraram interesse e estão em fase de aprovação pela Susep. Por outro lado, com o advento do Fundo de Catástrofe, segundo eles, as seguradoras e resseguradoras poderão adquirir cobertura suplementar para as suas carteiras de seguro rural, a ser utilizada no pagamento de indenizações decorrentes de eventos climáticos mais severos. Essa medida visa proporcionar uma ampliação da oferta de produtos de seguro rural no mercado, contribuindo para a diminuição do valor dos prêmios.

Como perspectiva para o PSR, segundo os gestores entrevistados, o governo estuda a criação de mecanismos adicionais de proteção agropecuária, de forma a garantir uma renda mínima ao produtor rural em caso de redução do preço da cultura segurada no mercado. Desta forma, o produtor rural estará protegido não somente contra as adversidades climáticas, mas também em relação às oscilações de preços da cultura segurada.

\section{Avaliação}

O primeiro ponto de avaliação de qualquer política pública deve ser a eficácia, que mede se a política alcançou seus objetivos propostos. Segundo o Decreto n. 5.121/2004, as diretrizes do PSR são: promover a universalização do acesso ao seguro rural, assegurar o papel do seguro rural como instrumento para a estabilidade da renda agropecuária e induzir o uso de tecnologias adequadas e modernizar a gestão do empreendimento agropecuário.

Os números demonstram que o Programa tem conseguido atrair a atenção do produtor rural para a importância da cobertura securitária privada. As alterações na implementação, como ampliação do número de culturas e do percen- 
tual subsidiado, cumpriram a função de elevar o número de produtores atendidos e a área coberta. Porém, conforme visto na Tabela 3, houve redução no número de produtores atendidos em 2010 com relação a 2009 em função da menor disponibilidade financeira para a subvenção. $\mathrm{O}$ orçamento disponibilizado atendeu apenas metade da demanda das seguradoras, aproximadamente, o que reforça que o problema maior está na quantidade de recursos para o Programa, e não na menor procura pelo Seguro Rural. Segundo o Relatório de Gestão Estratégica (BRASIL, 2010), a meta programada para 2010 em termos de área coberta pelo seguro rural alcançou $76 \%$ do esperado (de $10,32 \%$, se alcançou apenas 7,83\%). Desta forma, caso não sejam disponibilizados recursos suficientes para os próximos anos, é pequena a probabilidade de se obter, em 2015, 50\% da área agrícola coberta pelo seguro rural.

Os dados sobre capitais segurados - mais de R \$ 9,6 bilhões em 2009 e R \$ 6,5 bilhões em 2010 - demonstram que, de fato, o seguro rural é um instrumento para a estabilidade da renda em caso de sinistro. O projeto governamental de ampliar o escopo do PSR para atender, além de sinistros climáticos e sanitários, também a flutuações de preço dos produtos, se soma ao esforço de conformidade com os objetivos da Política Pública. Sobre a indução do uso de tecnologias adequadas, o PSR possui como condicionalidade a observância dos critérios de plantio definidos no zoneamento agrícola de risco climático, o que auxilia o produtor a conhecer quais culturas podem ser produzidas em quais regiões em determinadas janelas de plantio. De certa maneira, a própria adoção do seguro rural é uma forma de modernização da gestão do empreendimento agropecuário. Do ponto de vista da eficácia, portanto, os resultados são positivos, mas parciais.

Por ser um programa que concede subvenção ao Prêmio do Seguro Rural, não há o que se analisar em termos de economicidade, principalmente neste estágio inicial de implantação. A necessidade é disponibilizar mais recursos e de forma tempestiva, garantindo a adesão das seguradoras ao Programa. Com relação à eficiência econômica, pode-se medir tanto pela relação entre subvenção e importância assegurada, quanto pela diferença entre os sinistros pagos e a subvenção concedida. Porém, do ponto de vista do Programa, o ideal é que não haja uma grande quantidade de sinistros, pois isso poderia inviabilizar o mercado segurador. A análise, portanto, dar-se-á na relação Importância Segurada pela Subvenção Paga, conforme Tabela 4.

Os dados apontam que houve perda de eficiência econômica do PSR ao longo dos anos. Este fato é explicado pelas alterações realizadas durante a operacionalização, de modo a ampliar o número de produtores interessados em contratar o seguro rural. No caso de sinistro, o custo das perdas seria assumido pelas seguradoras, e não pelo governo. O resultado médio da relação entre importância segurada e subvenção concedida demonstra que, para cada $\mathrm{R} \$ 1,00$ investido pelo Programa, assegura-se aproximadamente R\$ 41,05. Portanto, o PSR demonstra boa eficiência econômica.

Tabela 4. Relação entre importância segurada e subvenção ao Prêmio do Seguro Rural, por ano

\begin{tabular}{|c|c|c|c|}
\hline Ano & $\begin{array}{l}\text { Subvenção } \\
\text { (R\$) }\end{array}$ & $\begin{array}{l}\text { Importância segurada } \\
\text { (R\$) }\end{array}$ & $\begin{array}{c}\text { Importância segurada / } \\
\text { Subvenção }\end{array}$ \\
\hline 2005 & 2.314 .919 & 126.637 .756 & 54,705 \\
\hline 2006 & 31.122 .161 & 2.869 .326 .074 & 92,196 \\
\hline 2007 & 60.961 .922 & 2.706 .036 .105 & 44,389 \\
\hline 2008 & 157.544 .950 & 7.209.176.951 & 45,759 \\
\hline 2009 & 259.610 .965 & 9.684 .244 .863 & 37,303 \\
\hline 2010 & 198.277.600 & 6.541 .634 .782 & 32,992 \\
\hline Total & 709.832 .517 & 29.137.056.531 & 41,047 \\
\hline
\end{tabular}

Fonte: Ministério da Agricultura, Pecuária e Abastecimento, 2010. 
Sobre o critério da equidade - homogeneidade de distribuição de benefícios/punições entre os destinatários de uma política pública, ainda há muito que se fazer, considerando os quase 25 milhões de hectares que ainda precisam ser incluídos. Mesmo assim, o Programa avançou consideravelmente em seus cinco anos de existência. $\mathrm{O}$ alcance das metas previstas se relaciona diretamente com as três questões principais a serem avaliadas neste trabalho (suficiência de recursos, instrumentos de gestão e participação social).

Com relação à suficiência de recursos, os dados da Tabela 3 demonstram que, a partir de 2009, este tem sido um grande problema do Programa, pois a demanda das seguradoras é superior à capacidade de atendimento por parte do governo federal. Enquanto em 2009 a diferença entre a demanda e o orçamento disponibilizado pelo Programa era de R\$ 100 milhões, em 2010, esse valor aumenta para R 222 milhões. Uma parte disso se deve ao fato de que o orçamento do PSR está vinculado ao orçamento do Mapa. Na medida em que o Ministério recebe contingenciamento, a subvenção recebe o mesmo tratamento. Uma possível solução, portanto, é desvincular um orçamento do outro, transformando o orçamento da subvenção em Operação Oficial de Crédito (2OC). O Programa continuaria sendo gerenciado pelo Ministério, mas sem comprometer seu orçamento.

Outra solução para a necessidade de ampliação dos recursos está na melhoria dos mecanismos de gestão. A lei que autoriza a concessão da subvenção estabelece um Comitê Gestor Interministerial do Seguro Rural. O Comitê tem papel deliberativo, e não apenas consultivo. Os Ministérios do Planejamento e da Fazenda, membros deste Comitê Gestor, também são os responsáveis pelas definições de orçamento e contingenciamento. Se os membros do Comitê Gestor aprovam Planos Trienais, então os órgãos orçamentários-financeiros devem considerá-los durante a elaboração da Lei Orçamentária Anual. Em outras palavras, os membros de Comitê Gestor devem ser capazes de efetivamente decidir e suas decisões devem ser cumpridas. Pelo que se percebe, porém, o Comitê Gestor não é utilizado efetivamente para gerir o Programa. Seus encontros são esporádicos, muitas vezes apenas para referendar decisões já tomadas, o que demonstra não haver muita eficiência administrativa. A recomendação, neste caso, é uma mudança na forma de condução da gestão do Programa por parte do Comitê Gestor.

Finalmente, sobre a participação social, percebe-se que ela ocorreu em diversos momentos, tanto na formulação quanto na implementação. $\mathrm{O}$ Fórum Permanente de Seguro Rural é um exemplo desta participação. O problema, no entanto, é que ela também ocorre de forma esporádica. Após a aprovação do marco regulatório, não foram obtidos mais documentos que demonstrem a continuidade deste fórum. A mesma situação foi observada com a Câmara Temática de Financiamento e Seguros do Agronegócio. A retomada de uma Câmara Temática para tratar apenas de seguro pode contribuir para uma participação social mais permanente.

\section{Conclusões}

A implementação do Programa de Subvenção ao Prêmio do Seguro Rural (PSR) ocorre num contexto de busca por novas formas de atuação do governo. Do ponto de vista econômico, reduz-se a necessidade de onerar o Tesouro Nacional com constantes renegociações de dívidas dos produtores rurais, na medida em que a contratação de uma apólice de seguro rural transfere os riscos advindos da atividade agropecuária para o setor securitário privado. Sob a ótica de formulação da política pública, o Programa inclui as partes interessadas em suas discussões, por meio do Fórum Permanente do Seguro Rural. Portanto, o PSR insere-se num misto de Administração Pública Gerencial (PEREIRA, 1996) - foco nas práticas gerenciais - e Administração Pública Societal (PAULA, 2005) - foco na participação social na formulação e implementação de políticas públicas.

Apesar de recente, o PSR vem produzindo resultados positivos se comparados com os obje- 
tivos propostos da Política Pública. O número de produtores atendidos e a área segurada têm se elevado nestes cinco anos. Em 2005, o PSR atendeu apenas 849 produtores. Em 2009, o número chegou a 56.306 produtores. Da mesma forma, a área segurada passou de 68.148 hectares em 2005 para 6.669.296 hectares em 2009. O decréscimo ocorrido no PSR em 2010 pode ser atribuído à falta de recursos que se iniciou em 2009. Para cobrir a diferença ocorrida em 2009, foi aprovado crédito suplementar para o Programa de Subvenção no valor de R\$ 90 milhões. Com a edição da lei, as seguradoras contrataram apólices já contando com os recursos da subvenção, porém, tais recursos não foram disponibilizados para o Ministério. Em 2010, a LOA aprovou recursos da ordem de R\$ 238 milhões, contudo, cerca de R\$ 82 milhões foram utilizados para pagar apólices pendentes do exercício de 2009. Como forma de repor esse valor, foi aprovado outro crédito suplementar de R\$ 90 milhões, disponibilizado apenas no final de 2010, comprometendo as contratações do seguro rural neste ano.

Atualmente, a eficácia do Programa, relativamente novo, é parcial. O interesse pela adesão ao Programa continua vigente. A análise de sua implementação demonstra sua necessidade e sua importância. É preciso, contudo, avançar em alguns pontos. O efetivo exercício do papel do Comitê Gestor Interministerial do Seguro Rural e a garantia dos recursos necessários de forma tempestiva são condições necessárias para o avanço da política pública. Sem eles, o instrumento perde a credibilidade do mercado segurador, o que pode comprometer essa política. Por outro lado, a participação social, por meio da Câmara Temática de Seguros do Agronegócio e de outros mecanismos, poderá contribuir com o aperfeiçoamento do Programa. O desafio é manter a interação de forma constante, para que não ocorra descontinuidade da nova Câmara.

\section{Referências bibliográficas}

ALMEIDA, W. S. de. Massificação das operações do seguro rural: o grande desafio brasileiro. Revista de Política Agrícola, Ano XVI, n. 4, 2007, p. 21-26.

BRASIL. Ministério da Agricultura, Pecuária e Abastecimento. Programa de subvenção ao prêmio do seguro rural: relatório 2010 / Ministério da Agricultura, Pecuária e Abastecimento. Secretaria de Política Agrícola. - Brasília: MAPA, 2011a. Disponível em <http://www.agricultura.gov.br/politica-agricola/ seguro-rural/relatorios > . Acesso em: 10 out. 2012.

BRASIL. Ministério da Agricultura, Pecuária e Abastecimento. Assessoria de Gestão Estratégica: Relatório de Gestão Estratégica 2010, Brasília: MAPA, 2011b.

BRASIL. Ministério da Agricultura, Pecuária e Abastecimento. Programa de subvenção ao prêmio do seguro rural: relatório 2009 / Ministério da Agricultura, Pecuária e Abastecimento. Secretaria de Política Agrícola. - Brasília: MAPA, 2010a. Disponível em <http://www.agricultura.gov.br/politica-agricola/ seguro-rural/relatorios > . Acesso em: 10 out. 2012.

BRASIL. Lei Complementar № 137, de 26 de agosto de 2010. Autoriza a participação da União em fundo destinado à cobertura suplementar dos riscos do seguro rural; altera dispositivos da Lei no 10.823 , de 19 de dezembro de 2003, da Lei Complementar no 126, de 15 de janeiro de 2007, do Decreto-Lei no 73, de 21 de novembro de 1966, do Decreto-Lei no 261, de 28 de fevereiro de 1967, e da Lei no 4.594, de 29 de dezembro de 1964; revoga dispositivos da Lei no 8.171, de 17 de janeiro de 1991, da Lei no 10.823, de 19 de dezembro de 2003, e do Decreto-Lei no 73, de 21 de novembro de 1966; e dá outras providências. Diário Oficial [da] República Federativa do Brasil, Brasília, 27 ago. 2010b.

BRASIL. Comitê Gestor Interministerial do Seguro Rural. Ata da 13a ${ }^{-}$Reunião Ordinária, Brasília, 25 nov. 2010c.

BRASIL. Comitê Gestor Interministerial do Seguro Rural. Ata da $12^{a}$ Reunião Ordinária, Brasília, 1o jun. 2010d.

BRASIL. Ministério da Agricultura, Pecuária e Abastecimento. Programa de subvenção ao prêmio do seguro rural: relatório 2008 / Ministério da Agricultura, Pecuária e Abastecimento. Secretaria de 
Política Agrícola. - Brasília: MAPA, 2009a. Disponível em: <http://www.agricultura.gov.br/politica-agricola/ seguro-rural/relatorios > . Acesso em: 10 out. 2012.

BRASIL. Ministério da Agricultura, Pecuária e Abastecimento. Plano estratégico / Ministério da Agricultura, Pecuária e Abastecimento. Assessoria de Gestão Estratégica. - 2. ed. - Brasília: Mapa/ACS, 2009b.

BRASIL. Decreto № 7.059, de 29 de dezembro de 2009. Aprova os percentuais e valores máximos da subvenção ao prêmio do seguro rural para o triênio 2010 a 2012. Diário Oficial [da] República Federativa do Brasil, Brasília, DF, 30 dez. 2009c.

BRASIL. Comitê Gestor Interministerial do Seguro Rural. Ata da 11a Reunião Ordinária. Brasília, 14 out. 2009d.

BRASIL. Comitê Gestor Interministerial do Seguro Rural. Ata da 10aㅡ Reunião Ordinária. Brasília, 19 ago. 2008.

BRASIL. Conselho Nacional de Seguros Privados. Resolução no 168, de 17 de dezembro de 2007. Dispõe sobre a atividade de resseguro, retrocessão e sua intermediação e dá outras providências.

BRASIL. Lei Complementar no 126 , de 15 de janeiro de 2007. Dispõe sobre a política de resseguro, retrocessão e sua intermediação, as operações de co-seguro, as contratações de seguro no exterior e as operações em moeda estrangeira do setor securitário; altera o Decreto-Lei no 73, de 21 de novembro de 1966, e a Lei no 8.031, de 12 de abril de 1990; e dá outras providências. Diário Oficial [da] República Federativa do Brasil, Brasília, 16 jan. 2007.

BRASIL. Comitê Gestor Interministerial do Seguro Rural. Ata da 9a Reunião Ordinária. Brasília, 07 dez. 2006a.

BRASIL. Comitê Gestor Interministerial do Seguro Rural. Ata da 8a Reunião Ordinária. Brasília, 04 jul. 2006b.

BRASIL. Comitê Gestor Interministerial do Seguro Rural. Ata da 7ª Reunião Ordinária. Brasília, 05 abr. 2006c.

BRASIL. Decreto 5.351, de 21 de janeiro de 2005. Aprova a Estrutura Regimental e o Quadro Demonstrativo dos Cargos em Comissão e das Funções Gratificadas do Ministério da Agricultura, Pecuária e Abastecimento, e dá outras providências. Diário Oficial [da] República Federativa do Brasil, Brasília, DF, 24 jan. 2005a.

BRASIL. Comitê Gestor Interministerial do Seguro Rural. Ata da 6 $6^{\underline{a}}$ Reunião Ordinária. Brasília, 1o set. 2005b.

BRASIL. Comitê Gestor Interministerial do Seguro Rural. Ata da 5ª Reunião Ordinária. Brasília, 02 jun. 2005c.
BRASIL. Comitê Gestor Interministerial do Seguro Rural. Ata da $4^{\text {a }}$ Reunião Ordinária. Brasília, 13 out. 2004a.

BRASIL. Comitê Gestor Interministerial do Seguro Rural. Ata da $3^{\mathrm{a}}$ Reunião Ordinária. Brasília, 14 set. 2004b.

BRASIL. Comitê Gestor Interministerial do Seguro Rural. Ata da $2^{\mathrm{a}}$ Reunião Ordinária. Brasília, $1^{\mathbf{0}}$ set. 2004c.

BRASIL. Comitê Gestor Interministerial do Seguro Rural. Ata da 1ํㅡㄹ Reunião Ordinária. Brasília, 18 ago. 2004d.

BRASIL. Decreto no 5.121, de 29 de junho de 2004. Regulamenta a Lei 10.823, de 19 de dezembro de 2003, que dispõe sobre a subvenção econômica ao prêmio do Seguro Rural e dá outras providências. Diário Oficial [da] República Federativa do Brasil, Brasília, DF, 30 jun. 2004e.

BRASIL. Lei № 10.823, de 19 de dezembro de 2003. Dispõe sobre a subvenção econômica ao prêmio do Seguro Rural e dá outras providências. Diário Oficial [da] República Federativa do Brasil, Brasília, DF, 22 dez. 2003.

BRASIL. Lei no 8.171, de 17 de janeiro de 1991. Dispõe sobre a política agrícola. Diário Oficial [da] República Federativa do Brasil, Brasília, DF, 18 jan. 1991.

BRASIL. Lei 5.969, de 12 de dezembro de 1973. Institui o Programa de Garantia da Atividade Agropecuária e dá outras providências. Diário Oficial [da] República Federativa do Brasil, Brasília, 12 dez. 1973.

BRASIL. Decreto-Lei no 73, de 21 de novembro de 1966. Dispõe sobre o Sistema Nacional de Seguros Privados, regula as operações de seguros e resseguros e dá outras providências. Diário Oficial [da] República Federativa do Brasil, Brasília, DF, 22 nov. 1966.

BRASIL. Lei no 2.168, de 11 de janeiro de 1954. Estabelece normas para instituição do seguro agrário. Diário Oficial [da] República Federativa do Brasil, Rio de Janeiro, 13 jan. 1954.

COTTA, T. C. Avaliação educacional e políticas públicas: a experiência do Sistema Nacional de Avaliação da Educação Básica (SAEB). Revista do Serviço Público, v. 52, n. 4, 2001, p. 89-111.

GUIMARÃES, M. F; NOGUEIRA, J. M. A experiência norte-americana com seguro agrícola: lições ao Brasil? Revista de Política Agrícola, Ano XVII, n. 2, 2008, p. 25-38.

OZAKI, V. A. Métodos atuariais aplicados à determinação da taxa de prêmio de contratos de seguro agrícola: um 
estudo de caso. 2005. Tese (Doutorado em Economia Aplicada) - Escola Superior de Agricultura Luiz de Queiroz, Universidade de São Paulo, Piracicaba, 2005. Disponível em: < http://www.teses.usp.br/teses/ disponiveis/11/11132/tde-11072005-160540/>. Acesso em: 10 out. 2012.

PAULA, A. P. P. de. Por uma Nova Gestão Pública: limites e potencialidades da experiência contemporânea. Rio de Janeiro: Editora FGV, 2005.
PEREIRA, L. C. B. Administração pública gerencial: estratégia e estrutura para um novo Estado. Brasília: MARE/ENAP, 1996.

ROSSETTI, L. A. Zoneamento agrícola em aplicações de crédito e securidade rural no Brasil: aspectos atuariais e de política agrícola. Revista Brasileira de Agrometeorologia, v. 9, n. 3, 2001, p. 386-399.

SECCHI, L. Políticas públicas: conceitos, esquemas de análise, casos práticos. São Paulo: Cengage Learning, 2010. 